Association on Mental Deficiency (AAMD). The concept of mild retardation is quantitative and embraces, using conventional standards, some $2.2 \%$ of the population in addition to the $0.4 \%$ who are even less gifted. Not all of this considerable population is in receipt of special services, even at school age; but prospects for training for skilled employment and independent social adaptation tend to be limited. Fortunately, the AAMD has omitted from the revised classification of mental handicap" the term "borderline mental retardation," but this is still in common use and embraces much of the "dull normal" stream.

It seems contrary to the general sense of the leading article thus arbitrarily to exclude any causal role in mental retardation to malnutrition when this can admittedly cause some deficiency in the developing brain. It would seem more reasonable in the present state of science to keep an open mind on this question and to view it as one of the many possible modes of operation of the impact of adverse social and economic factors among underprivileged groups and disadvantaged classes.

BRIAN KIRMAN

Queen Mary's Hospital for Children,

Carshalton, Surrey

${ }^{1}$ Manual on Terminology and Classification in Mental Retardation, ed K J Grossman. Washington, DC, American Association on Mental Deficiency, 1973.

\section{Factors affecting length of hospital stay}

SIR,-May I comment on Mr H B J Chishick's second letter (17 June, p 1622) as his first (29 April, p 1145) referred to a letter of mine (25 March, p 789)?

$\mathrm{He}$ seems to share the common delusion that the only obstacle to reducing the waiting time for cold surgery is "unnecessary delay in discharging patients." This is almost never true because the real limiting factor nowadays is the work capacity of the operating theatres and anaesthetic services (perhaps not the latter in cataract surgery). To dwell on figures of bed occupancy, turnover intervals, mean duration of patient stay, or cost per patient is a great waste of many well-meaning people's time, and generates a vast amount of totally unproductive heat.

Roger Hole

Department of Urology,

North Ormesby Hospital,

\section{Effects on fetus of stilboestrol in} pregnancy

SIR,-With reference to the paper by $\mathrm{Mr}$ $M$ Monaghan and $\mathrm{Mr} \mathrm{L} \mathrm{A}$ W Sirisena (17 June, p 1588) your readers may be interested to know of research carried out by Henderson et $a l^{1}$ in the USA into whether there was higher incidence of abnormalities in the sons of women who had taken diethylstilboestro (DES) during their pregnancies as compared with the sons of controls.

They found that the only significan difference was in the incidence of diseases of the urogenital tract-55 out of 225 exposed males $(25 \%)$ compared with 17 out of 111 controls $(15 \%)$. Their most striking finding was the difference in incidence of abnormalities of the penile urethra-10 of the exposed males compared with none of the unexposed males. These abnormalities con- sisted of one case of hypospadias (the number which could be expected among the total of 306 males surveyed) and nine cases of urethral stenosis, a finding which was highly significant.

No cases of malignancy have been reported, but this is presumably not yet ruled out as a possibility owing to the youth of the subjects involved. No systematic follow-up of such patients is possible in the USA since there is on centralised record keeping. This could perhaps be undertaken in the UK since it appears that many women who took DES are already known and could therefore be contacted for information concerning their sons.

VALERIE HaRTLEy-BREWER

London N3

${ }^{1}$ Henderson, B E, et al, Pediatrics, 1976, 58, 505

\section{Inappropriate use of tricyclic} antidepressants

SIR,-The short report by Dr J C Little and others (17 June, $p$ 1593) pointing out their difficulty in obtaining depressed patients for a clinical trial raises an important question. They requested general practitioners to refer those patients whom the GP thought suitable for tricyclic antidepressant therapy. The table in the report shows that 12 of the 35 patients referred $\left(33^{\circ}{ }_{0}\right)$ were either unsuitable for treatment with tricyclics or were suffering from conditions in which tricyclic treatment was actually contraindicated. If these patients had not been referred for these specific investigations their GPs would presumably have initiated tricyclic therapy and this suggests that there may be a disturbingly high inappropriate use of these drugs in general practice.

Harefield Hospital,
Uxbridge, Middx

JOHN R KIRWAN

"Innovation in the Pharmaceutical Industry"

SIR,-Dr B W Cromie (17 June, p 1618) corroborates the views expressed at a Council for International Organisations of Medical Sciences/World Health Organisation meeting six months ago on "Trends and prospects in drug research," at which speakers with knowledge of the pharmaceutical industry were uniformly pessimistic. ${ }^{1}$

As he indicates, there are many contributory factors besides the drug control authorities. However well intentioned in dividually, the constraints have collectively created a paradoxical situation in which the industry is no longer able to develop the drugs that society needs. The cost, delays, and uncertainties make drug research progressively less attractive and the large multidivisional enterprises that make up the research-based industry now see other more promising areas for investment than pharmaceuticals. Once they start to run down their investment the industry will rapidly decline and would take years to rebuild.

In the past the industry has attracted a great deal of criticism, but it has largely been responsible for the tremendous therapeutic advances of the past 30 years. It still offers the best prospect for further progress, but if the profession, politicians, and public want progress to continue they must promote or at least permit a climate in which a vigorous industry can operate. This is the fundamental problem and it is urgent.

T B BINNS

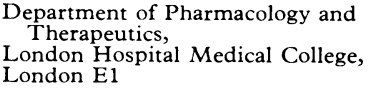

${ }^{1}$ Lancet, 1977, 2, 1335.

\section{Utility of needle aspiration of tumours}

SIR,-One statement bothers me in your excellent leading article on this subject (10 June, $p$ 1507) although I admit that from the surgeon's point of view it is probably true that "when challenged, most of those who seek cytological specimens would agree that a histopathological diagnosis is necessary before ablative surgery or other radical treatment, such as chemotherapy or radiotherapy." However, from the cytopathologist's point of view when surgical biopsy fails to confirm a positive diagnosis of carcinoma made on needle aspiration cytology biopsy of the tumour must be repeated in order to find the malignant tissue. False-positive cytological diagnoses of cancer are very rare in my experience, giving this procedure a specificity of almost $100^{\circ}{ }_{0}$. The drawbacks of aspiration cytology compared with surgical biopsy are (1) its lower sensitivity-that is, more false-negative reportsand (2) its narrower diagnostic facility-for example, adenocarcinoma cannot be so readily differentiated from squamous carcinoma. On the other hand it needs no anaesthetic and it can be done on outpatients at negligible cost.

P A TrotT

\section{Department of Pathology,}

Royal Marsden Hospital,

London SW3

\section{Factors influencing the incidence of} neonatal jaundice

SIR,-Dr B S B Wood (3 June, p 1488) criticises our study on neonatal jaundice (13 May, p 1235) because it was retrospective. However, while accepting that a prospective study is preferable, the large number of cases included strengthens the value of our conclusions and a prospective study of 12000 neonates would be expensive and time consuming to carry out. Our arbitrary allocation of an average normal bilirubin level to those infants in whom the measurement was not considered necessary is said to be "not acceptable." This procedure merely allowed us further to quantify the importance of the different factors found to be independently associated with changes in the jaundice rate and it did not bias the identification of these factors.

Dr Wood reports that breast-feeding produces a twofold increase in jaundice and we did not study the influence of breast-feeding. We have now been able to add this factor to our analysis for 9300 babies born between 1971 and 1975. The breast-feeding rate was $55^{\circ}$ and significant jaundice $\geqslant 205 \mathrm{\mu mol} /$ $(\geqslant 12 \mathrm{mg} / 100 \mathrm{ml})$ ) was detected in $13.2 \%$ of breast-fed and $11.4 \%$ of bottle-fed infants Multivariate analysis confirmed breast-feeding as an independent factor associated with increased jaundice, but the estimated average increase in peak bilirubin concentration due to it was only $5 \mu \mathrm{mol} / 1(0.3 \mathrm{mg} / 100 \mathrm{ml})$. This 